\title{
High-throughput, low-cost, and event-specific polymerase chain reaction detection of herbicide tolerance in genetically modified soybean A2704-12
}

\author{
H. Ma ${ }^{1,2}$, H. Li ${ }^{2,3,4}$, J. Li ${ }^{2,4}$, X.F. Wang ${ }^{2}$, P.C. Wei ${ }^{2,3}$, L. Li ${ }^{2}$ and J.B. Yang ${ }^{2}$ \\ ${ }^{1}$ College of Life Sciences, Anhui Agricultural University, Hefei, China \\ ${ }^{2}$ GMOs and Derived Products Inspection and Supervision Center (Hefei), \\ Ministry of Agriculture/Key Laboratory of Rice Genetics Breeding of Anhui \\ Province/Rice Research Institute, Anhui Academy of Agricultural Sciences, \\ Hefei, China
}

${ }^{3}$ Institute of Agricultural Engineering, Anhui Academy of Agricultural Sciences, Hefei, China

${ }^{4}$ Key Laboratory of Ion Beam Bioengineering,

Institute of Technical Biology and Agriculture Engineering,

Chinese Academy of Sciences, Hefei, China

Corresponding author: J.B. Yang

E-mail: yjianbo@263.net

Genet. Mol. Res. 13 (1): 696-703 (2014)

Received January 31, 2013

Accepted July 31, 2013

Published January 28, 2013

DOI http://dx.doi.org/10.4238/2014.January.28.14

\begin{abstract}
The aim of this study was to develop an event-specific qualitative and real-time quantitative polymerase chain reaction (PCR) method for detection of herbicide-tolerance genetically modified (GM) soybean A2704-12. The event-specific PCR primers were designed, based on the 5'-flanking integration sequence in the soybean genome, to amplify the 239-bp target fragment. Employing the same event-specific primers, qualitative PCR and real-time quantitative PCR detection methods were
\end{abstract}


successfully developed. The results showed that the A2704-12 event could be specifically distinguished from other GM soybean events. In the qualitative PCR assay, the limit of detection was $0.05 \%$, and in the real-time quantitative PCR assay, the limit of detection was less than $0.01 \%$. Moreover, our genomic DNA (gDNA) extraction protocol is highthroughput, safe, and low-cost. The event-specific PCR assay system is costefficient by using SYBR Green I in real-time PCR, and by using the same primers in both the qualitative and quantitative PCR assays. We therefore developed a high-throughput, low-cost, and event-specific qualitative and quantitative PCR detection method for GM soybean A2704-12. The method would be useful for market supervision and management of GM soybean A2704-12 due to its high specificity and sensitivity.

Key words: Genetically modified soybean A2704-12; Event-specific; Herbicide-tolerance; High-throughput; Qualitative; Quantitative

\section{INTRODUCTION}

Genetically modified (GM) crops can make important contributions to global food security and sustainable development. The area of GM crops reached 160 million hectares in 2011. GM soybean (Glycine max) continued to be the principal GM crop in 2011, occupying $47 \%$ of the total area of global GM crops. Herbicide tolerance has consistently been the dominant trait in GM crops (James, 2011). The herbicide-tolerant GM soybean line A2704-12 was initially developed by Bayer CropScience. This soybean line has been genetically modified by the introduction and expression of the pat gene, which confers tolerance to herbicides containing the active ingredient glufosinate ammonium. GM soybean line A2704-12 has been approved for cultivation for feed and food in the major soybean producing countries, such as China, Brazil, Argentina, and the US (Ma et al., 2011a; Marinho et al., 2012).

The number of approved GM crops is continuously growing (James, 2011). However, in order to strengthen the regulations of genetically modified organisms (GMOs), more than 50 countries and areas have published a series of laws and rules for GMO regulations and mandatory labeling. Therefore, the easy and reliable detection of GM crops is of particular applied significance.

Many detection methods have been developed to date based on either DNA detection or protein detection (Nascimento et al., 2012). However, DNA amplification by polymerase chain reaction (PCR) is the most commonly used method worldwide. Conventional PCR is able to qualitatively detect GMOs, whereas the real-time PCR method can be used to quantitatively detect GMOs for better quantitative performance, greater sensitivity, and accuracy (Ma et al., 2011a; Maciel et al., 2011). The detection of specific elements such as promoters, coding sequences, and terminators can be very helpful for identifying GMOs. Nevertheless, the detection of specific elements cannot distinguish the different GM events involving the same specific elements. Therefore, the event-specific PCR detection method was used for GMO detection because of its high specificity for the flanking sequence of the inserted DNA fragment (Yang et al., 2005).

Although some methods have previously been used to detect herbicide resistance in GM soybean A2704-12, these methods were low-throughput, costly, and/or not event-specific. Therefore, the aim of this study was to develop a high-throughput, low-cost, and event-specific method to detect herbicide resistance GM soybean A2704-12 using both conventional and real-time PCR assays. 


\section{MATERIAL AND METHODS}

\section{Soybean samples}

Seeds of A2704-12 and other GM soybean events (A5547-127, MON89788, and GTS40-3-2) were used. Seeds of the non-GM soybean cultivar A2704 were used as the negative control. To obtain leaf samples, seeds were cultured in an incubator under light.

\section{Event-specific PCR primers design}

The 5'-flanking sequence of the inserted fragment in A2704-12 was determined using thermal asymmetric interlaced PCR (TAIL-PCR) (Liu et al., 1995). The primers were designed with Primer Express 3.0 software (Life Technologies, CA, USA). The design of eventspecific PCR primers for A2704-12 is shown in Figure 1. The primers were synthesized (Life Technologies), and their sequences are shown in Table 1. The soybean lectin gene (GenBank accession No. K00821) was chosen as the endogenous reference gene.

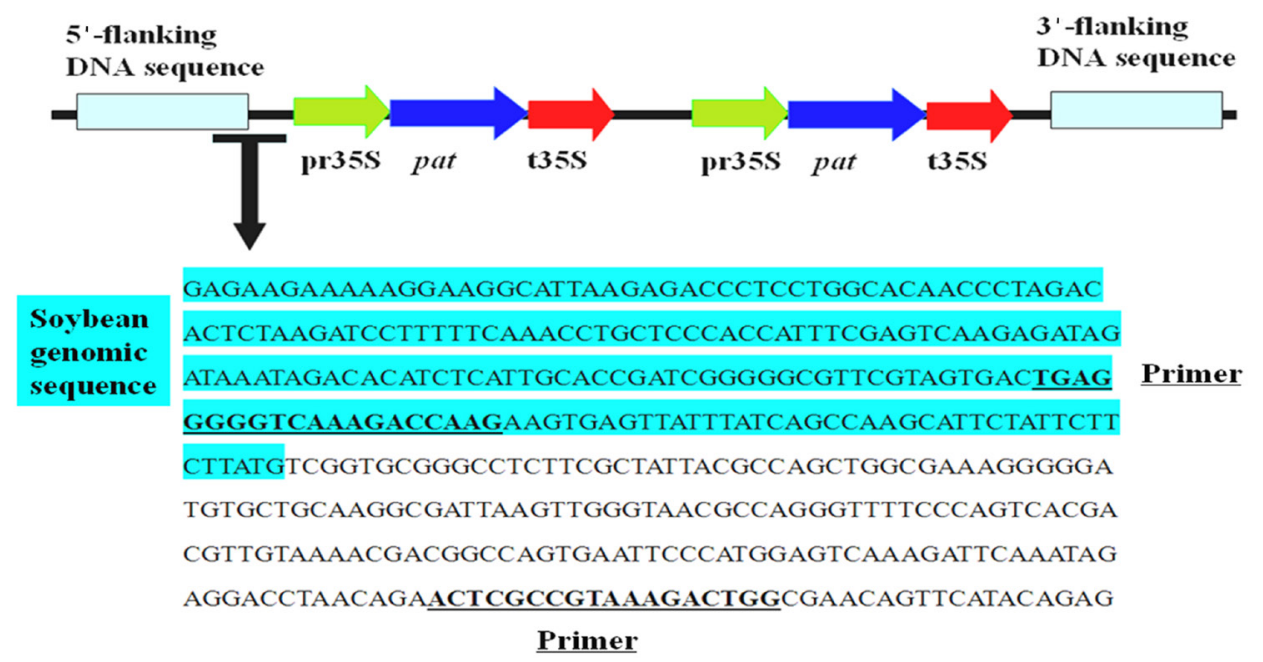

Figure 1. Design of event-specific PCR primers for A2704-12.

Table 1. Oligonucleotide primers sequence used for qualitative and quantitative PCR detection.

\begin{tabular}{llc}
\hline Primer name & Sequence (5' to 3') & Amplicon (bp) \\
\hline A2704-F & TGAGGGGGTCAAAGACCAAG & 239 \\
A2704-R & CCAGTCTTTACGGCGAGT & 244 \\
Lectin-F & ACCAGCAAGGCAAACTCAGC & \\
Lectin-R & AGTTGAAGGAAGCGGCGAAG & \\
\hline
\end{tabular}

\section{DNA extraction}

For high-throughput genomic DNA (gDNA) extraction, 10-20 mg soybean leaf sample 
or $50 \mathrm{mg}$ soybean seed powder was placed in a 96-well deep well block. The seed powder was prepared according to the method of Kamiya and Kiguchi (2003). The high-throughput gDNA extraction procedure used was described in a previous report (Li et al., 2012). Briefly, the sample was suspended in $300 \mu \mathrm{L}$ extraction buffer (100 mM Tris-HCl, pH 8.0, 50 mM EDTA, pH 8.0, 1 $\mathrm{M} \mathrm{NaCl}$, and $1.25 \%$ sodium dodecyl sulfate, with the addition of $1 \%$ 2-mercaptoethanol before use), then vigorously vortexed for $1 \mathrm{~min}$. Next, $150 \mu \mathrm{L} 5 \mathrm{M}$ potassium acetate was added to the tube, and vigorously vortexed again for $1 \mathrm{~min}$. The suspension was centrifuged for $10 \mathrm{~min}$ at $12,000 \mathrm{x} g$, then $300 \mu \mathrm{L}$ supernatant was transferred to a new block with $200 \mu \mathrm{L}$ isopropanol in each well. The suspension was centrifuged for $10 \mathrm{~min}$ at $12,000 \mathrm{x}$. The supernatant was discarded, and the DNA was washed with $600 \mu \mathrm{L} 70 \%$ ethanol, and air-dried on a clean bench. The DNA was dissolved in $150 \mu \mathrm{L} 0.1 \mathrm{X}$ TE buffer $(1 \mathrm{mM}$ Tris-HCl, $\mathrm{pH} 8.0$, and $0.1 \mathrm{mM}$ EDTA, $\mathrm{pH}$ 8.0). The DNA concentration was determined using a NanoDrop 2000 spectrophotometer (Thermo Scientific, DE) according to manufacturer protocol.

\section{Qualitative PCR assays}

In qualitative PCR assays, the amplifications were carried out in $20 \mu \mathrm{L}$ volume reactions, with $2 \mu \mathrm{L}$ DNA samples, $1 \mathrm{X}$ PCR buffer (10 mM Tris-HCl, $\mathrm{pH} 8.3$, and $1.5 \mathrm{mM} \mathrm{MgCl}$ ), $250 \mu \mathrm{M}$ dNTP mix, $200 \mathrm{nM}$ each primer, and $1 \mathrm{U}$ Taq DNA polymerase (Takara, Dalian, China). The PCR amplifications were performed in the GeneAmp PCR 9700 system (Life Technologies) with the following program: denaturation at $95^{\circ} \mathrm{C}$ for $5 \mathrm{~min}, 35$ cycles of $30 \mathrm{~s}$ at $94^{\circ} \mathrm{C}, 30 \mathrm{~s}$ at $58^{\circ} \mathrm{C}, 30 \mathrm{~s}$ at $72^{\circ} \mathrm{C}$; extension at $72^{\circ} \mathrm{C}$ for $7 \mathrm{~min}$. Amplification products were electrophoresed on $2 \%$ agarose gels at $100 \mathrm{~V}$ for $25 \mathrm{~min}$ on $1 \mathrm{X}$ TAE (Tris-base, glacial acetic acid, EDTA) gel buffer. The gel was stained with $0.25 \mu \mathrm{g} / \mathrm{mL}$ ethidium bromide for DNA visualization.

\section{Real-time quantitative PCR assays}

Real-time PCR was performed on an Applied Biosystems 7500 Real Time PCR System (Life Technologies). Amplification was carried out in a total volume of $20 \mu \mathrm{L}$, containing 200 nM primers, 1X SYBR ${ }^{\circledR}$ Premix Ex Taq ${ }^{\mathrm{TM}}$ II (Takara), 1 X ROX reference dye (Takara), and $4 \mu \mathrm{L}$ DNA templates (or different dilution samples), brought up to volume with nuclease-free water. Amplification was carried out using the following program: $3 \mathrm{~min}$ at $95^{\circ} \mathrm{C}$ for pre-denaturation, then 40 cycles of $5 \mathrm{~s}$ at $95^{\circ} \mathrm{C}$ and $34 \mathrm{~s}$ at $60^{\circ} \mathrm{C}$. After PCR amplification, dissociation curve analysis was performed as follows: the PCR products were heated to $95^{\circ} \mathrm{C}$ for $1 \mathrm{~min}$, cooled at $60^{\circ} \mathrm{C}$ for $1 \mathrm{~min}$, and then slowly heated to $95^{\circ} \mathrm{C}$ at a rate of $0.2^{\circ} \mathrm{C} / \mathrm{s}$. The threshold cycle $\left(\mathrm{C}_{\mathrm{T}}\right)$ values were automatically calculated with the 7500 software version 2.0.5 (Life Technologies).

\section{Specificity and limit of detection (LOD) of event-specific PCR assays}

To determine the specificity, the genomic DNA samples from the different GM soybeans (A2704-12, A5547-127, GTS40-3-2, and MON89788) were detected by event-specific qualitative and quantitative PCR.

To determine the LOD, a $50 \mathrm{ng} / \mu \mathrm{L}$ gDNA sample of A2704-12 was diluted with $0.1 \mathrm{X}$ TE buffer to obtain a dilution series: 10-fold, 100-fold, 200-fold, 1000-fold, 2000-fold, and 10,000-fold. The mass concentrations (w/v) of A2704-12 genomic DNA were 10, 1, 0.5, 0.1, 0.05, and 0.01\%. 
In qualitative and real-time quantitative PCR assays, the positive control (PC) was the sequenced plasmid DNA, which contained the 5'-flanking sequence of the inserted fragment in A2704-12. The negative control (NC) was genomic DNA of the non-GM soybean cultivar, A2704. The plasmid or gDNA concentration of each sample was diluted to $50 \mathrm{ng} / \mu \mathrm{L}$ with $0.1 \mathrm{X}$ TE buffer. In order to exclude the false positive results, no template control (NTC) and single primer controls (SPC) were used in qualitative and real-time quantitative PCR assays.

\section{RESULTS AND DISCUSSION}

\section{DNA extraction}

Typically, DNA samples have an A260/A280 ratio > 1.8 and an A260/A230 ratio > 2.0, which indicate that the DNA quality is sufficient for further examination (Sambrook and Russell, 2001). In this study, the A260/A280 ratio ranged from 1.87 to 2.10, and the A260/ A230 ratio ranged from 2.01 to 2.18. These results showed that the DNA had little contamination of protein, polysaccharides, or polyphenols, which would inhibit the enzymatic activity of DNA polymerase and affect PCR amplification efficiency (Li et al., 2012). Most gDNA extraction methods are based on the microcentrifuge tube format. Our extraction procedure provides high throughput by using a 96-well block to isolate gDNA. The extracted gDNA was sufficient with respect to quantity and purity for conventional and real-time PCR assays.

\section{Specificity and LOD of the qualitative PCR assay}

PCR amplification revealed the target 239 bp fragment with a clear and sharp band (Figure 2). Successful PCR amplification also indicated that the gDNA was of high quality and amplifiable. The fragment was obtained from GM soybean A2704-12, and no amplification product was observed from the other GM soybeans (A5547-127, MON89788, and GTS40-32), SPC, NC, or NTC (Figure 2). These data indicated that the target $239 \mathrm{bp}$ DNA fragment was unique to A2704-12. In other words, this qualitative PCR assay was the event-specific PCR assay for GM soybean A2704-12.

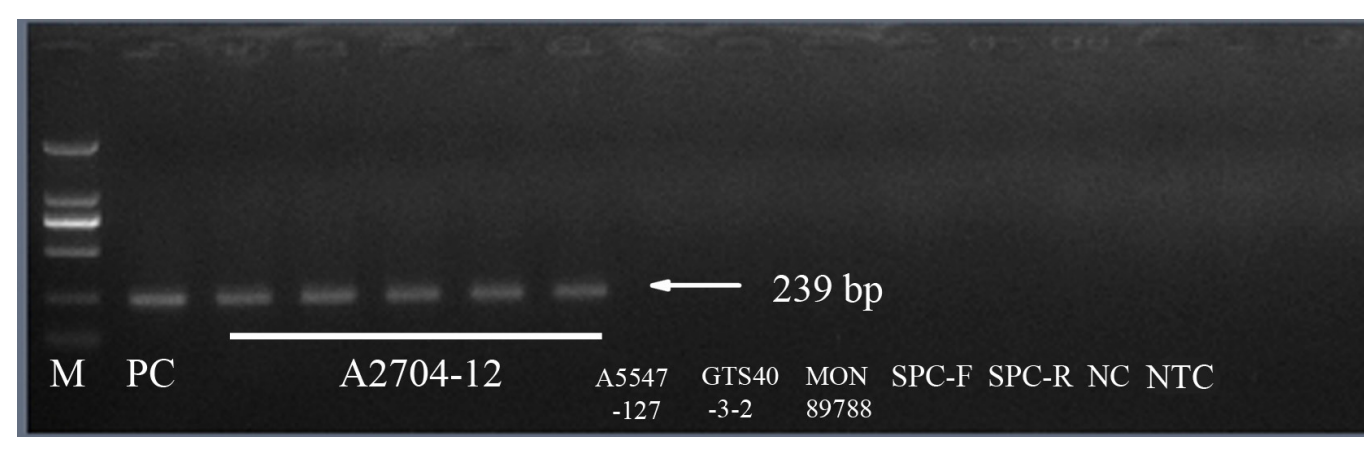

Figure 2. Specificity of event-specific qualitative PCR for A2704-12. Lane $M=$ DL2000 marker; PC = positive control; A2704-12 = different lines of A2704-12; SPC-F = simple A2704-F primer control; SPC-R = simple A2704-R primer control; $\mathrm{NC}=$ negative control; NTC $=$ no template control. 
In order to determine the LOD of the event-specific qualitative PCR assay, the 50 $\mathrm{ng} / \mu \mathrm{L}$ gDNA sample of A2704-12 was diluted. The mass concentrations (w/v) of A2704-12 gDNA were $10,1,0.5,0.1,0.05$ and $0.01 \%$. Figure 3 shows that the target fragment could not be detected in the $0.01 \%$ concentration (Figure 3 ). This indicated that the LOD of the eventspecific qualitative PCR assay for GM soybean A2704-12 was 0.05\%.

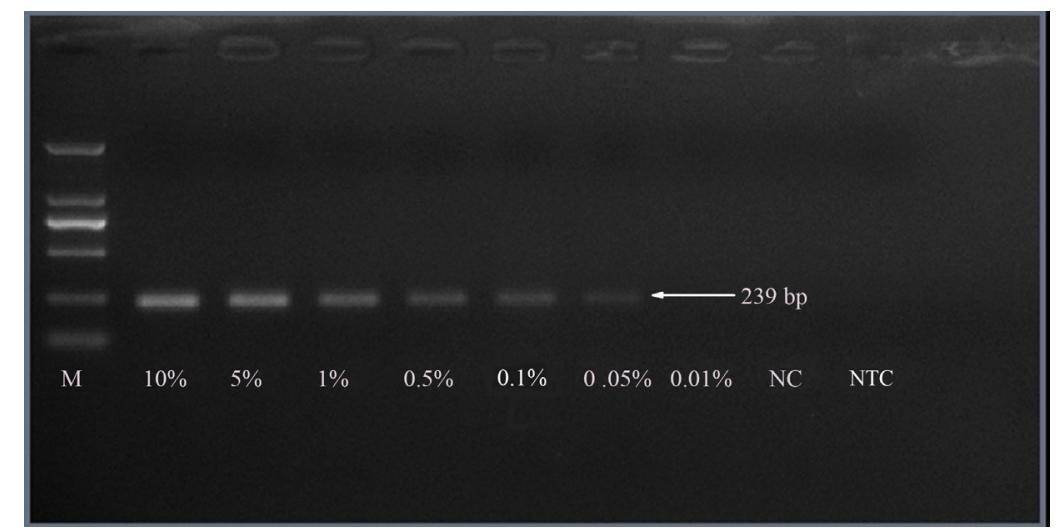

Figure 3. LOD of event-specific qualitative PCR for A2704-12. Lane $M=$ DL2000 marker; 10, 5, 1, 0.5, 0.1, 0.05, and $0.01 \%$ : the mass concentration (w/v) of A2704-12 genomic DNA was 10, 1, 0.5, 0.1, 0.05, and 0.01\%; $\mathrm{NC}=$ negative control; NTC $=$ no template control.

\section{Specificity and LOD of the real-time quantitative PCR assay}

The results of the real-time quantitative PCR assay are shown in Table 2. The realtime quantitative PCR assay was also event-specific for GM soybean A2704-12 (Table 2). The fluorescent signal was undetermined from the other GM soybeans (A5547-127, MON89788, and GTS40-3-2), SPC, NC, and NTC (Table 2).

Table 2. Event-specific qualitative and real-time quantitative PCR results for A2704-12.

\begin{tabular}{lccc}
\hline Samples & $\mathrm{C}_{\mathrm{T}}{ }^{*}$ & $\mathrm{C}_{\mathrm{T}}$-Lectin* & Qualitative PCR \\
\hline A2704-12 $(100 \%)$ & $26.47 \pm 0.14$ & $26.55 \pm 0.11$ & + \\
A2704-12 $(10 \%)$ & $29.39 \pm 0.11$ & $29.29 \pm 0.08$ & + \\
A2704-12 $(1 \%)$ & $31.86 \pm 0.09$ & $31.78 \pm 0.12$ & + \\
A2704-12(0.5\%) & $32.79 \pm 0.13$ & $32.68 \pm 0.13$ & + \\
A2704-12(0.1\%) & $35.20 \pm 0.14$ & $35.09 \pm 0.15$ & + \\
A2704-12 $(0.05 \%)$ & $36.22 \pm 0.16$ & $36.02 \pm 0.14$ & + \\
A2704-12(0.01\%) & $38.98 \pm 0.18$ & $38.87 \pm 0.20$ & - \\
A5547-127 & - & $26.64 \pm 0.08$ & - \\
GTS40-3-2 & - & $26.57 \pm 0.09$ & - \\
MON89788 & $17.25 \pm 0.04$ & $26.34 \pm 0.05$ & - \\
PC & - & - & - \\
NC & - & $26.54 \pm 0.05$ & - \\
NTC & - & - & - \\
SPC-F & - & - & - \\
SPC-R & & - & \\
\hline
\end{tabular}

The symbol + signifies where product was detected. The symbol - signifies no product detected. *Means $\pm \mathrm{SD}, \mathrm{N}=$ 6. $\mathrm{C}_{\mathrm{T}}$-Lectin was the $\mathrm{C}_{\mathrm{T}}$ value of reference lectin gene. $\mathrm{PC}=$ positive control of the sequenced plasmid $\mathrm{DNA}$. $\mathrm{NC}=$ negative control of non-GM soybean cultivar A2704. NTC $=$ no template control of water. SPC-F $=$ single primer control of A2704-F or Lectin-F. SPC-R = single primer control of A2704-R or Lectin-R. 
The LOD of the real-time quantitative PCR assay for GM soybean A2704-12 was less than $0.01 \%$ (Table 2). Overall, the real-time quantitative PCR assay showed uniform eventspecific results and higher sensitivity compared to the qualitative PCR assay.

\section{Evaluation of the event-specific PCR assays for A2704-12}

Obtaining DNA of high quality is necessary for achieving reproducible results in conventional and real-time PCR assays (Cankar et al., 2006). Using a 96-well block, our gDNA extraction procedure provided high-throughput for isolating gDNA from a large number of plant samples. Our protocol does not require phenol-chloroform and liquid nitrogen or dry ice. Moreover, phenol in gDNA samples would inhibit the enzymatic activity of DNA polymerase, and affects PCR amplification efficiency ( $\mathrm{Li}$ et al., 2012). Therefore, our gDNA extraction protocol is high-throughput, safe, and low-cost. Furthermore, the extracted gDNA is sufficient in quantity and purity for real-time PCR.

Real-time PCR has become an indispensable analytical platform for nucleic acid quantification owing to its quantitative performance, sensitivity, and accuracy. SYBR Green I, a commonly used fluorescent DNA binding dye, has been used widely in real-time PCR assays (Maciel et al., 2011). In this study, we chose the same primers for the qualitative and real-time quantitative PCR assays, and employed SYBR Green I in real-time quantitative PCR. Therefore, the assay system is cost-efficient. Simple primer PCR correction is helpful in eliminating false positive results in PCR amplification (Ma et al., 2011b). In this study, SPC was not detected in either the qualitative or real-time quantitative PCR assays. Therefore, the primers used in this study are specific for detecting the target fragment.

PCR-based GMO detection methods can be divided into four categories: screening, gene-specific, construct-specific, and event-specific PCR methods (Zhang et al., 2012). The target fragment of event-specific PCR lies in the junction at the integration locus between the recipient genome and the inserted DNA. The 5'-flanking or 3'-flanking sequence at the integration locus is event-specific. Many event-specific PCR methods have been established to detect several GM crops, including rice, maize, and soybean (Zhang et al., 2012). In this study, based on the 5'-flanking sequence, the event-specific primers were designed to amplify the 239-bp target fragment. The qualitative and real-time quantitative PCR assays showed uniform eventspecific results for GM soybean A2704-12.

In conclusion, we developed a high-throughput, low-cost, and event-specific qualitative and quantitative PCR detection method for GM soybean A2704-12. Due to its specificity and sensitivity, this method should be useful for GM soybean A2704-12 detection, regulation, and labeling.

\section{ACKNOWLEDGMENTS}

Research supported by the National Key Technology R\&D Program of China in the 12th Five-Year Plan Period (Grant \#2012BAD07B01-4), the Youth Foundations of President of the Anhui Agricultural Academy of Sciences (Grant \#13B0101, \#13B0114), and the Creative Team Foundation of the Anhui Agricultural Academy of Sciences (Grant \#13C0101).

\section{REFERENCES}

Cankar K, Štebih D, Dreo T, Žel J, et al. (2006). Critical points of DNA quantification by real-time PCR - effects of DNA extraction method and sample matrix on quantification of genetically modified organisms. BMC Biotechnol. 6: 37. 
James C (2011). Global Status of Commercialized Biotech/GM Crops: 2011. ISAAA Brief No. 43, ISAAA: Ithaca, New York.

Kamiya M and Kiguchi T (2003). Rapid DNA extraction method from soybean seeds. Breed. Sci. 53: 277-279.

Li H, Li J, Cong XH and Duan YB (2013). A high-throughput, high-quality plant genomic DNA extraction protocol. Genet. Mol. Res. 12: 4526-4539.

Liu YG, Mitsukawa N, Oosumi T and Whittier RF (1995). Efficient isolation and mapping of Arabidopsis thaliana T-DNA insert junctions by thermal asymmetric interlaced PCR. Plant J. 8: 457-463.

Ma H, Wang XF, Li L and Lu XZ (2011a). Establishment of an event-specific qualitative PCR method for detection of herbicide-tolerance genetically modified soybean A2704-12. Mol. Plant Breed. 9: 376-380.

Ma J, Wang PW, Yao D, Wang YP, et al. (2011b). Single-primer PCR correction: a strategy for false-positive exclusion. Genet. Mol. Res. 10: 150-159.

Maciel BM, Dias JC, Romano CC, Sriranganathan N, et al. (2011). Detection of Salmonella Enteritidis in asymptomatic carrier animals: comparison of quantitative real-time PCR and bacteriological culture methods. Genet. Mol. Res. 10: 2578-2588.

Marinho CD, Martins FJ, Amaral Junior AT, Goncalves LS, et al. (2012). Use of transgenic seeds in Brazilian agriculture and concentration of agricultural production to large agribusinesses. Genet. Mol. Res. 11: 1861-1880.

Nascimento VE, Von Pinho EV, Von Pinho RG and do Nascimento ADJ (2012). Detection limits of the strip test and PCR for genetically modified corn in Brazil. Genet. Mol. Res. 11: 2497-2505.

Sambrook J and Russell DW (2001). Molecular Cloning, a Laboratory Manual. Cold Spring Harbor Laboratory Press, Cold Spring Harbor, New York.

Yang L, Xu S, Pan A, Yin C, et al. (2005). Event specific qualitative and quantitative polymerase chain reaction detection of genetically modified MON863 maize based on the 5'-transgene integration sequence. J. Agric. Food Chem. 53: 9312-9318.

Zhang M, Huo N, Liu Y and Qiu Y (2012). Event-specific detection of genetically modified wheat B73-6-1 based on the 3'-flanking sequence. Eur. Food Res. Technol. 235: 1149-1159. 